\title{
LO QUE NO PODEMOS HACERNOS EL UNO AL OTRO. SOBRE EL PERDÓN Y LA VULNERABILIDAD MORAL
}

\author{
Christel Fricke* \\ doi:10.11144/Javeriana.uph32-64.uopv
}

\section{RESUMEN}

Típicamente, el perdón se convierte en un problema cuando un ofensor ha dañado a una víctima. Cuando se comprometen en un proceso de dar y conceder perdón, al ofensor y a su víctima les interesan las relaciones sociales que previamente existieron entre ellos. Partiendo del trasfondo de estas relaciones surge la pregunta de si para la víctima perdonar es un deber y si el ofensor tiene el derecho de ser perdonado. Sugiero distinguir entre relaciones personales y morales entre personas: las morales vinculan a todo agente racional a la comunidad de todos los agentes morales, mientras que las primeras son de carácter personal. En este sentido, distingo entre perdón personal y moral. Y discuto que el ofensor tiene derecho a ser moralmente perdonado, o por la misma víctima o por otro miembro de la comunidad de agentes morales; pero la víctima no tiene un deber de perdonar personalmente al ofensor.

Palabras clave: perdón; vulnerabilidad moral; daño; víctima; ofensor

* Universidad de Oslo, Oslo, Noruega.

Correo electrónico: christel.fricke@csmn.uio.no

La presente traducción al castellano, realizada por David Martínez Rincón, Universidad de Antioquia (Medellín-Colombia), procede del capítulo del libro en inglés: Fricke, Ch. (2011) What we cannot do to each other. On forgiveness and moral vulnerability. Ch. Fricke. (Ed.), The Ethics of Forgiveness: A Collection of Essays (pp. 51-68). New York/London: Routledge. El traductor agradece a Maria Alejandra Carrasco por la revisión de la traducción; a John Gómez, Luis Javier Villegas y Liliana Molina por su lectura atenta de la traducción, y a Diego Pineda por facilitar esta publicación. Para citar este artículo: Fricke, Ch. (2015). Lo que no podemos hacernos el uno al otro. Sobre el perdón y la vulnerabilidad moral. Universitas Philosophica, 32(64), pp. 125-152, ISSN 0120-5323, ISSN en línea: 2346-2426, doi: 10.11144/ Javeriana.uph32-64.uopv

Esta traducción se hizo en el marco de la investigación (en curso) titulada: Mal moraly perdón como una respuesta posible ética ante el daño, financiada por el CODI (Comité para el desarrollo de la investigación de la Universidad de Antioquia) y dirigida por Liliana Molina González, Profesora del Instituto de Filosofía de la Universidad de Antioquia e investigadora del grupo Cultura, Violencia $y$ Territorio, del Instituto de Estudios Regionales (INER). 


\title{
WHAT WE CANNOT DO TO EACH OTHER. ON FORGIVENESS AND MORAL VULNERABILITY
}

\author{
Christel Fricke
}

\begin{abstract}
Forgiveness typically becomes an issue where an offender has wronged a victim. What the offender and his victim are concerned with when engaging in a process of asking for and granting forgiveness includes the social relations that previously existed between them. It is against the background of these relations that the question arises whether there can be a duty for a victim to forgive and a right for an offender to be forgiven. I suggest distinguishing between personal and moral relations between people; the latter bind every rational agent to the community of all moral agents, whereas the former are a personal matter. Accordingly, I distinguish between personal and moral forgiveness. And I argue that the offender has a right to be morally forgiven, either by the victim herself or by another member of the community of moral agents; but the victim does not have a duty to forgive the offender personally.
\end{abstract}

Key words: forgiveness; moral vulnerability; wrongdoing; victim; offender 
El perdón en cuanto es gobernado por normas sociales y morales

TípiCAMENTE, EL PERdón SE CONVIERTE EN UN PROBLEMA cuando se ha hecho un mal (wrong), cuando una persona intencionalmente $-\mathrm{o}$ al menos con conocimiento- ha dañado (wronged) a otro ${ }^{1}$. Es debido a nuestra vulnerabilidad por la que, a veces, llegamos a ser víctimas del mal que hacen (wrongdoing) otros. Si todos fuéramos invulnerables, el daño (wrongdoing) no sería posible y no habría necesidad de pedir o conceder el perdón. El daño (damage) que causa una acción mala (wrongdoing) puede ser de diversos tipos. En cuanto criaturas corporales podemos sufrir daño físico. Cuando la propiedad privada se ha institucionalizado y podemos poseer bienes materiales somos, en cuanto propietarios, materialmente vulnerables. Finalmente, como criaturas conscientes ${ }^{2}$, podemos también sufrir daño psíquico; podemos sufrir traumas. El daño físico, material o psíquico que sufrimos no tiene que ser necesariamente causado por el obrar intencionalmente malo de otra persona. Puede deberse a causas naturales como, por ejemplo, un terremoto. Cuando estos daños obedecen a causas naturales, no tiene sentido que la víctima reaccione con sentimientos tales como resentimiento personal, ira u odio; ni con afecciones motivacionales que la lleven a la retaliación o la venganza -aunque la víctima puede, no obstante, responder con tales afectos $^{3}$. Estos sentimientos solo tienen sentido cuando los daños han sido causados por acciones intencionales de otras personas; y, cuando no solo hay una víctima, sino también un agresor. El perdón es típicamente un problema (issue) entre una víctima y su ofensor.

1 Sin embargo, la existencia de un daño actual no es condición necesaria para que el perdón sea un tema. Véase la contribución de Espen Gamlund en el capítulo 7 de The Ethics of Forgiveness: $A$ Collection of Essays. Respecto a la distinción entre perjuicio (harm) no intencional e intencional, véase Hampton, 1988, pp. 43-44.

2 Traduzco "mind" por "consciente" excluyendo la posibilidad de emplear el término "alma", pues este último tiene un sentido sustancial al que puede aludir en castellano y en la historia de la filosofía. "Mind" en el lenguaje ordinario tiene el sentido de lo que nos permite ser conscientes del mundo. (N. del T.)

3 Por ejemplo, puede pensarse en los amigos de una persona que muere tras estrellar su auto con un árbol. Los amigos podrían talar el árbol para satisfacer su necesidad emocional de retaliación. Pero un árbol no es un objeto apropiado de sentimientos reactivos tales como el resentimiento, la ira o el odio. 
Para reparar el daño físico, tenemos que confiar o en la propia capacidad que tiene el cuerpo de sanarse ${ }^{4}$ o en la ayuda médica. Los objetos de nuestra posesión también pueden ser dañados o destruidos. Las pérdidas materiales pueden recuperarse o reparando o reemplazando los objetos respectivos. El daño psíquico, al menos en algunos casos, puede sanarse con algún tipo de psicoterapia. Frecuentemente, después de un terremoto las personas están afectadas en estos tres sentidos y, entonces, hay mucho trabajo para los médicos, los removedores de escombros, los constructores y los psicoterapeutas. Sin embargo, en los casos de un mal (wrongdoing) intencional, no es el daño físico, material o psíquico que sufre la víctima en sí mismo lo que está en juego, sino las relaciones sociales que existían previamente entre el agresor y su víctima y, en alguna medida, también algunas de las relaciones sociales adicionales que vinculan a ambos con otros miembros de la comunidad ${ }^{5}$ a la que pertenecen. En consecuencia, el daño intencional afecta al ser social (social being) de la víctima y del agresor en la medida en que este había sido configurado por las relaciones sociales que previamente existían entre ellos y con los otros miembros de su respectiva comunidad ${ }^{6}$. Al obrar mal, el agresor no solo ha dañado a su víctima, sino que también ha violado las normas que gobiernan las relaciones sociales constitutivas de su comunidad. Tal violación representa una clase particular de daño psíquico no solo para la víctima, sino también para el agresor: obrar mal incluye tanto un acto de dañar a otro (other damage) como un acto de dañarse a sí mismo (self-damage). Puede pensar-

4 Traduzco "to heal" por "sanar" en vez de "curar". Sanar hace referencia a la salud (del cuerpo y del alma) y proviene del término latino "sanare" que tiene una relación con el término inglés "to heal" y "health" en tanto ambos aluden a la salud o a estar libre de enfermedad o lesiones. Descarto el término "curar" que en castellano tiene el sentido de cuidado y que proviene del latín "curare", es decir, cuidar. (N. del T.)

5 Traduzco "social network" como "comunidad" y, en algunos casos, como "grupo". Es importante advertir que no se trata solo de una comunidad o de un grupo, sino que la autora se refiere a los lazos que hay entre los distintos miembros. Por ello, una alternativa es traducir tejido social o red social. Para hacer la traducción más natural traduzco, en general, como comunidad indicando aquí que la autora se refiere a los lazos, al tejido o a la red de una sociedad. (N. del T.)

6 Margaret Urban Walker ya llamaba la atención al respecto diciendo que: "cuando nosotros u otros somos lastimados o maltratados no se trata del hecho del daño (harm) o el sufrimiento en sí mismo, sino del sentido de la maldad (wrongfulness) de ese daño o del sufrimiento que es incorporado en esta clase de ira" (Walker, 2006, p. 25). Sobre el rol del ser relacional en los procesos de perdón véase también Atkins, 2002, p. 112, 118ss., y Norlock, 2009, pp. 41-69. 
se, por ejemplo, en un matrimonio con hijos pequeños. Si uno de los padres viola la promesa de fidelidad hecha al otro, y este se siente humillado y profundamente lastimado, lo que está en juego no es solo la pareja y sus sentimientos de humillación y dolor emocional. El daño también alcanza a las relaciones sociales que constituyen la pareja, y el que fue infiel también daña su propio ser social en la medida en que este incluye su rol de compañero en el matrimonio. Asimismo, las relaciones entre los padres y sus hijos se afectan, tal como las relaciones entre todos los miembros de las familias unidas por este matrimonio 7 .

Al obrar mal, el agresor manifiesta que él no es digno de la confianza de su víctima ni de la de los otros miembros del grupo social al que ambos pertenecen: no se puede seguir confiando en que él respetará las normas que subyacen a las relaciones sociales de este grupo. La víctima, en particular, no puede relacionarse con su agresor como lo hacía antes porque ha perdido la confianza en él. Para restablecer la confianza mutua, las relaciones sociales entre el agresor y su víctima tienen que ser reparadas o redefinidas. Su futuro común puede tomar la forma de una relación de renovada cercanía o de una más o menos remota coexistencia. El proceso del perdón, si es exitoso, allana el camino para que el agresor, su víctima, y los otros miembros de su respectiva comunidad, restablezcan la confianza mutua.

Algunos casos de daño constituyen una violación de las normas legales. Un agente que viola una norma legal puede tener que enfrentar un juicio y un castigo legal. El tipo y grado de castigo dependerá de la gravedad de su crimen. Después de cumplir la condena (excluyendo la pena de muerte o la cadena perpetua), será readmitido como miembro con plenos derechos en la sociedad cuyas reglas legales había violado -al menos así sucede en los países de Europa Occidental-. La víctima de su mala acción no puede evitar esta readmisión formal. Después de todo, las instituciones legales quitan de las manos de las víctimas el derecho y el deber de castigar.

Pero las normas legales no cubren todas las clases posibles de daño. Tampoco el castigo legal sana todas las heridas psíquicas de la víctima ni ayuda al agresor a subsanar su remordimiento y el daño que se hizo a sí mismo, ni tampoco ayuda a redefinir las relaciones sociales entre el agresor, la víctima y los otros miembros

7 Explorar los múltiples efectos destructivos del adulterio es el principal interés de la novela de Theodor Fontane Unwiederbringlich. 
de la comunidad. Aquí es donde el perdón entra en escena. El perdón no juega ningún papel en los tribunales. Sin embargo, fuera de ellos el agresor puede pedir a la víctima que lo perdone, y la víctima puede concederle o no ese perdón. Típicamente, el perdón es un proceso comunicativo entre un agresor y su víctima que, cuando es exitoso, les permite a ambos dejar la ofensa atrás, subsanar sus respectivos sentimientos de resentimiento y remordimiento, y definir los términos de su futura relación de un modo que no esté exclusivamente determinado por la ofensa pasada ${ }^{8}$.

Según Charles Griswold, el perdón "está gobernado por normas", las que él entiende en términos de normas morales. Para Griswold, el perdón es "una relación moral entre dos individuos, uno de los cuales ha hecho daño al otro, y que (al menos idealmente) tienen la capacidad de comunicarse entre sí" (Griswold, 2007, pp. xv-xvi, la cursiva es mía). Al mismo tiempo, Griswold (2007, p. 54) es consciente del hecho que el perdón cumple una función terapéutica importante respecto de las heridas psíquicas causadas por el daño intencionado y que deben ser sanadas. Como "programa terapéutico" el perdón es tema de estudios psicológicos que normalmente se centran en el punto de vista de la víctima del obrar mal9 ${ }^{9}$ El análisis de Griswold sobre el perdón en cuanto es gobernado por normas morales se basa en el supuesto "de nuestra vulnerabilidad ante los otros"; y, en cuanto se concentra en el perdón moral, este supuesto implica la afirmación de que somos moralmente vulnerables entre nosotros (Griswold, 2007, p. 44). Pero, ¿en qué sentido somos moralmente vulnerables y con respecto a quiénes?

Lo que distingue a las normas morales - entendidas en nuestro sentido occidental e igualitario del término- de otras normas sociales es que se aplican a todos los seres humanos, independientemente del rol social específico que cumplen en el grupo particular al que pertenecen. Mientras las normas sociales se configu-

8 El proceso de perdón puede darse también en circunstancias atípicas: cuando el agresor y la víctima son la misma persona (el perdón de sí mismo), cuando el ofensor no es responsable o no lo es completamente por el daño que causó, cuando el agresor o la víctima han muerto o bien existen otras razones que imposibilitan un proceso comunicativo, o cuando ni la víctima ni el ofensor sobreviven. Siguiendo el propósito de este ensayo, dejo de lado muchas de estas clases atípicas del perdón. Para una discusión que puede ser de mucha ayuda respecto a estos casos véase: Griswold, 2007, Caps. 3, 4, 5.

9 Para un resumen sobre el debate respecto al rol que el perdón puede jugar en la psicoterapia véase: Lamb y Murphy, 2002. 
ran de acuerdo con los diversos modos en que las personas de hecho se relacionan entre sí; las normas morales son supuestamente configuradas por el modo en que las personas deberian relacionarse entre sí, independientemente del rol más específico que cumplan en un grupo social particular. Esta es una distinción fundamental: una persona cumple un rol social porque está relacionada con los otros de cierto modo, pero una persona es en primer lugar un ser moral y debería, por consiguiente, relacionarse como tal con los otros. El estatus moral de una persona no depende del grupo social al que pertenece; antes bien, su estatus moral debería configurar el modo en que se relaciona con los otros ${ }^{10}$.

Nuestra comprensión occidental e igualitaria de la moralidad se basa en la suposición de que todos los seres humanos tenemos un valor moral intrínseco o dignidad. En cuanto seres con dignidad moral, tenemos un derecho intrínseco a ser moralmente respetados y un deber intrínseco a respetar el valor moral de otros. La atribución de dignidad a un ser humano no depende de si él cumple actualmente con su deber moral y respeta del mismo modo la dignidad moral de todas las otras personas, o en qué medida lo hace. La dignidad moral no depende del mérito moral. La dignidad moral tampoco depende de que una persona realmente goce del respeto que otras personas están obligadas a prestarle. La dignidad moral no es un estatus social intrínseco. Una persona que sufre de toda clase de faltas de respeto, que es intencionalmente lastimada o perjudicada por otros, no perderá su dignidad moral por el hecho de ser dañada (wronged), aun cuando sí podría perder su salud mental y, particularmente, su salud emocional y su capacidad para desempeñarse como un agente con responsabilidad moral plena. La dignidad moral de un ser humano está fuera del alcance de cualquier maltrato que esta persona pueda sufrir. Los seres humanos que se entienden como portadores de valor intrínseco o dignidad moral son moralmente invulnerables ${ }^{11}$.

10 Hampton, en su explicación del perdón, llama la atención sobre la pluralidad de normas sociales que existen en diferentes culturas; sin embargo, propone varias concepciones del valor humano de un mismo nivel, sin darse cuenta de la diferencia intrínseca que existe entre, por un parte, concepciones del valor humano igualitarias y basadas en la dignidad y, por otra, concepciones no igualitarias y basadas en las diferencias entre roles sociales. Véase: Hampton, 1988.

11 Este punto ya ha sido anteriormente señalado, aunque no ha sido suficientemente considerado en los debates contemporáneos sobre el perdón y sus restricciones normativas. Véase, en particular, Hampton, 1988, p. 35; Hill, 2000, pp. 92, 95, 106, 110ss.; Govier, 2002, pp. 164-168; Hampton: 2007, pp. 30-72; Murphy, 2009, p. 573. 
Griswold restringe la invulnerabilidad moral al hombre perfectamente virtuoso, tal como se le ha concebido en el pensamiento pagano antiguo. Su ejemplo de una concepción de persona moral que excluye la vulnerabilidad moral de la persona es el del hombre idealmente virtuoso de las teorías morales perfeccionistas, como la de Aristóteles: "el caballero (gentleman) que posee la perfección de la virtud moral -el megalopsuchos- no solo [no tiene] ${ }^{12}$ la necesidad (por su propia luz) de ser perdonado, porque por definición es moralmente perfecto"; sino que este hombre "también parecería no dar el perdón a los otros", en parte porque él se "juzgaría a sí mismo inmune de ser dañado moralmente por los otros" (Griswold, 2007, p. 8). Sin embargo, al caracterizar al hombre perfectamente virtuoso, Aristóteles no tenía la intención de representar a los seres humanos comunes. Los seres humanos comunes no serían suficientemente virtuosos. Lo que Aristóteles tenía en mente era un ideal moral que todo ser humano moralmente ambicioso debería intentar alcanzar ${ }^{13}$.

El hombre perfectamente virtuoso es una persona moral en virtud de su perfección moral actual. Su perfección moral le hace moralmente invulnerable: está fuera del alcance del daño moral realizado por sí mismo o por otros. Como - por definición- no daña a nadie, no puede dañar su propia perfección moral. Y ningún otro puede dañar su perfección moral porque, o los otros son igualmente perfectos y tampoco dañarían a nadie, o son menos perfectos y, por consiguiente, demasiado bajos y moralmente insignificantes como para estar en posición de dañar al hombre perfectamente virtuoso. No obstante, mientras la invulnerabilidad moral del hombre perfectamente virtuoso depende de que por definición el ser de este hombre no tiene falla moral, la invulnerabilidad moral de la persona moral cuya moralidad está basada en la dignidad moral no depende de su perfección moral actual. No depende de ningún tipo de condiciones que los seres humanos sean incapaces de cumplir.

12 Los corchetes indican la interpolación de Fricke en el texto de Aristóteles. (N. del T.)

13 En estas consideraciones solo me apoyo en lo que Griswold dice sobre el megalopsuchos de Aristóteles. No pretendo comenzar una discusión respecto de la interpretación de la ética de Aristóteles. 
Uno de los padres intelectuales de nuestra comprensión de la dignidad moral es Emmanuel Kant. En el $\$ 38$ de “La doctrina de la virtud”, de su Metafísica de las costumbres, escribe:

Todo hombre tiene un legítimo derecho al respeto de sus semejantes y también él está obligado a lo mismo, recíprocamente, con respecto a cada uno de ellos. La humanidad misma es una dignidad; porque el hombre no puede ser utilizado únicamente como medio por ningún hombre (ni por otros, ni siquiera por sí mismo), sino siempre a la vez como fin, y en esto consiste precisamente su dignidad (la personalidad), en virtud de la cual se eleva sobre todos los demás seres del mundo que no son hombres y sí que pueden utilizarse, por consiguiente, se eleva sobre todas las $\cos ^{2}{ }^{14}$. (AA VI, 462)

Según Kant, nuestra dignidad intrínseca o valor moral es compatible con nuestra imperfección moral actual. Cada vez que fracasamos en respetar la dignidad de una persona, fracasamos en vivir a la altura de nuestra propia dignidad moral. Pero este fracaso no quiere decir que dañemos la dignidad de la persona a quien no respetamos ni que perdamos la nuestra. La dignidad de los otros está más allá de nuestro alcance y, por consiguiente, no representamos ningún peligro para su dignidad. Según Kant, "lo peligroso no es objeto de desprecio y por eso no lo es tampoco el hombre vicioso; y si mi superioridad sobre sus ataques me autoriza a decir: le desprecio, esto solo significa que aunque no me defendiera de él, no hay ningún peligro, porque él mismo muestra su vileza" (AA VI, 463).

Tampoco el obrar mal moral aniquila la dignidad del agresor, pues, para el filósofo de Königsberg, "yo no puedo negar ni siquiera al vicioso, en tanto que hombre, el respeto que no puede quitársele, al menos en calidad de hombre; aunque con su acción se haga sin duda indigno de él” (AA VI, 463).

La dignidad que, según Kant, cada ser humano tiene simplemente en virtud de ser un ser humano es una fuente de derechos morales y de deberes morales y ninguna falta de respeto actual de estos derechos y deberes puede destruirla ${ }^{15}$. Contraria-

14 La versión es de Adela Cortina Orts quien traduce directamente del texto kantiano alemán y realizo sutiles modificaciones que siguen la traducción de Fricke. (N. del T.)

15 Dillon entiende de una manera errónea esta afirmación kantiana sobre la dignidad humana como consideración psicológica (más que como una consideración a priori de un estatus normativo y moral). Véase: Dillon, 2001, p. 70. Respecto a la dignidad y la invulnerabilidad moral, véase: Winch, 1966 y Duff, 1976. 
mente a la concepción aristotélica del hombre perfectamente virtuoso, la moralidad de un ser humano, como Kant la entiende, no es solo un ideal; todo ser humano tiene un valor moral intrínseco y por tanto debe ser tratado con respeto moral.

Un análisis filosófico del perdón en cuanto gobernado por normas morales tiene que tomar en consideración nuestra comprensión no-meritocrática del valor que tiene cada ser humano. Pero no puede dirigirse a las personas exclusivamente en términos de su valor moral a priori, porque en estos términos todas son invulnerables y, por consiguiente, nunca podrían estar en la posición de una víctima o de un agresor. Las personas moralmente invulnerables no necesitan pedir perdón ni concederlo, porque no son seres intrínsecamente sociales. Solo como seres corpóreos con mente, quienes somos miembros de una sociedad humana somos social y moralmente vulnerables ${ }^{16}$. Los papeles de víctima y de agresor son roles sociales. La pregunta es cómo nuestra práctica social y nuestro trato con actos de obrar mal en particular deberían ser informados por nuestro valor moral intrínseco o dignidad. Dado el valor moral intrínseco de todas las personas, ¿tiene el agresor un derecho moral a ser perdonado? y ¿tiene la víctima un deber moral a conceder el perdón? Para responder estas preguntas se debe explicar la diferencia que hace, tanto para el agresor como para su víctima, que se logre o no el perdón.

Las consecuencias del obrar mal y la diferencia que marca el perdón

LAS PREGUNTAS SOBRE LO CORRECTO y lo incorrecto están típicamente relacionadas con personas que viven en sociedades: sus acciones tienen consecuencias para otros. Como miembros de una sociedad, las personas normalmente actúan de acuerdo con las normas de esa sociedad, al menos lo suficiente si esta sociedad no se desmorona. Las normas sociales no tienen que ser morales en nuestro sentido igualitario y no-meritocrático del término ${ }^{17}$. Pero si las normas sociales de una sociedad incluyen normas que prescriben el respeto universal a la dignidad o valor moral intrínseco de cada ser humano, y si estas normas son mutuamente consistentes, entonces estas normas pueden considerarse confor-

16 Sobre esto ha hecho hincapié Atkins, quien se refiere en sus análisis sobre vulnerabilidad y perdón a Merleau-Ponty. Véase: Atkins, 2002, p. 118ss.

17 Véase: Harbsmeier, 2011, pp. 13-29. 
mes con las demandas de la moralidad ${ }^{18}$. Las normas sociales, aun cuando son compatibles con el respeto universal a todas las personas que las normas morales prescriben, son constituidas por los miembros de las sociedades y se aplican a los miembros de esa sociedad. Estas normas establecen estándares para la conducta correcta e incorrecta de los miembros de un grupo particular e implícitamente distinguen también a estos miembros como miembros grupales del resto de las personas. Las normas sociales difieren entre culturas. Pero incluso en una misma cultura hay subculturas de subgrupos que definen sus propias normas sociales $\mathrm{y}$, por consiguiente, se distinguen de otros miembros de la misma sociedad. Por ejemplo, están las distintas culturas juveniles cuyos miembros se reconocen entre sí y se distinguen de los extraños por medio de determinados códigos de vestir, del tipo de música que escuchan y los clubes en que se reúnen. La pareja matrimonial, los padres y sus hijos, los amigos, los colegas o los miembros de un club, todos actúan conforme a normas sociales específicas que prescriben cierta clase de conducta a esas personas, y solo a ellas. Estas normas sociales específicas desempeñan un papel crucial en determinar el rol social que una persona tiene en una comunidad. Obviamente, una persona puede tener más de un rol social y los deberes impuestos por estos roles sociales pueden a veces entrar en conflicto. Por ejemplo, un padre con un trabajo exigente puede sentir la presión de las demandas a veces incompatibles de su pareja y sus hijos, por un lado, y de sus colegas, por el otro.

Las normas sociales típicamente definen lo que se considera correcto e incorrecto especificando lo que es moralmente correcto e incorrecto, o bien añadiendo distinciones normativas a las normas morales. Ejemplos de estas normas adicionales pueden ser las normas para los modales en la mesa o los códigos de vestir. Pero en el contexto de este artículo nos interesan particularmente las normas sociales que representan especificaciones de las normas morales. De este modo un esposo está vinculado a su esposa (y viceversa) de un modo especial y no está vinculado del mismo modo con ninguna otra persona. Los padres están normalmente vinculados por responsabilidades específicas que tienen con sus hijos. Las promesas que hacemos a individuos particulares y las responsabilidades que tenemos con individuos particulares crean vínculos sociales entre las personas. Las personas vinculadas por tales relaciones sociales específicas son particular-

18 Hill, 2000, pp. 87-151; Govier, 2002, pp. 164-168; Murphy, 2009, p. 573. 
mente vulnerables entre sí. Su vulnerabilidad se incrementa proporcionalmente según esos vínculos sociales. Perjudicar y lastimar a una persona con quien se está unido por relaciones sociales cercanas es moralmente incorrecto, como lo es perjudicar o lastimar a cualquiera. Sin embargo, el perjuicio específico no debe entenderse solo en términos morales, sino también en términos de la relación más específica que ha sido dañada por la persona responsable del perjuicio. Lo que las personas juzgan como incorrecto depende no solo de las normas morales, sino también de las normas sociales de la sociedad a la que pertenecen. Si es moralmente incorrecto para dos personas tener relaciones sexuales depende de si se compenetra o no con el respeto mutuo que ellos se deben como personas morales. Si es socialmente incorrecto, depende de si representa o no una violación de las normas sociales más específicas de la sociedad respectiva. Las sociedades difieren mucho con respecto a sus reglas sobre relaciones sexuales. Cuando se trata de juicios normativos sobre lo correcto y lo incorrecto, no es fácil separar el punto de vista moral del punto de vista social: lo que se considera como una conducta respetuosa o sin respeto está de manera frecuente determinado socialmente. Sin embargo, distinguir entre normas morales en general y normas sociales específicas es fundamental al momento de entender las restricciones normativas del perdón.

Las normas sociales definen las expectativas que todos los miembros de una sociedad particular tienen respecto del comportamiento de los otros miembros de la misma sociedad: todos esperan que los demás actúen de acuerdo con estas normas y son conscientes de que los demás también esperan que él o ella hagan lo mismo. La motivación personal para tal respeto es fortalecida por las instituciones policiales y jurídicas. Además, puede haber otras normas que deban ser respetadas por miembros particulares de una sociedad, según las diferentes relaciones personales entre ellos, tales como las relaciones familiares, las relaciones entre amigos, colegas o los miembros del mismo club social. Un acto de obrar mal tiene múltiples consecuencias que deben entenderse en el complejo marco de las normas morales en general y de las normas sociales de una sociedad particular. Por otro lado, cuando la víctima y el agresor estaban unidos en una relación más personal, las normas más específicas que subyacían al tipo de relación personal que los unía deben ser también consideradas.

Está, en primer lugar, la víctima del acto de obrar mal. La víctima sufre perjuicio (harm) físico, material o psíquico. Adicionalmente, la víctima siente que su 
valor moral intrínseco no fue respetado por el autor del perjuicio y, cuando, al mismo tiempo, las relaciones más personales han sido también dañadas, la víctima se siente no respetada como miembro de una familia, como un amigo o como un colega. Podría también sentirse no respetada en algún otro rol social que cumple dentro de su comunidad. Así es como una profesora podría sufrir la falta de respeto no solo por parte de sus colegas, sino también de sus estudiantes; y, si en el mismo periodo de su vida tampoco es respetada por su pareja o sus amigos, estará en un serio peligro de deprimirse o sufrir una crisis nerviosa. Como consecuencia de la experiencia de no ser respetada, una persona podría sentir dañado (damaged) su ser social y su correspondiente respeto de sí. Después de todo, la realidad psíquica del propio respeto depende más de nuestra experiencia del respeto que nos brindan los otros que de nuestro valor moral intrínseco ${ }^{19}$. Si no fuera así, nuestro ser social y respeto de nosotros mismos no podría ser dañado (damage) por la experiencia del obrar mal de otra persona. Como respuesta a la mala acción del otro, la víctima no puede seguir confiando en que el agresor respetará su valor moral intrínseco (esto es, el de la víctima); tampoco puede confiar en que el agresor actuará exclusivamente de acuerdo con las normas de la respectiva sociedad; ni tampoco, en caso en que antes tuviera una relación personal con el agresor, puede confiar más en él como un miembro de la familia, como un amigo o como un colega. La víctima normalmente responde a la experiencia del obrar mal con sentimientos de resentimiento, ira o hasta odio. Culpará al agresor y posiblemente se encontrará en un estado afectivo que podría inducirlo a buscar la retaliación y la venganza. El agresor, por su parte, confrontado con las consecuencias de su acción mala como un hecho irreversible del pasado; confrontado con el resentimiento, la ira, la culpa y, eventualmente, con el odio de la víctima y la perspectiva de su retaliación y venganza; y, confrontado quizás, también, con la posibilidad de ser culpado en público por la víctima, puede sentirse mal con lo que le hizo. Por supuesto, podría intentar negar que dañó a la víctima o negar que la haya dañado (wronged) deliberadamente. Pero si nada de esto le resultara, sentirá remordimiento ${ }^{20}$. Los objetos posibles de este remordimiento son múltiples, incluyen el perjuicio ( $\mathrm{harm}$ ) hecho a la víctima; la falta de respeto mostrado a la

19 Holmgren pasa por alto este punto. Véase: Holmgren, 1993, 1998 y 2002.

20 Dejo de lado el caso particular del amoral que es incapaz de cualquier clase de sentimiento moral. 
víctima en cuanto un ser humano intrínsecamente valioso; la falta de respeto en cuanto un miembro de la misma sociedad y, eventualmente, en cuanto contraparte en una relación cercana. Además, incluirá el daño hecho a la relación de confianza que existía previamente entre ambos. Los objetos del remordimiento del agresor también lo incluyen a él mismo como un agente moralmente responsable, que adhirió a normas sociales y morales, y que se valora a sí mismo como una persona vinculada por tales normas; y, después de todo, fracasó en vivir el deber que tiene como tal agente, el deber de respetar a las otras personas con un valor moral intrínseco y el deber más específico que surge de las relaciones sociales particulares. El agresor no solo decepciona las expectativas de otras personas y de la víctima, sino que también se decepciona a sí mismo. Cuando un agente moralmente responsable daña a otra persona, no solo daña intrínsecamente a su víctima sino que también se daña a sí mismo, a su rol social y el correspondiente respeto de sí mismo. Finalmente, pero no menos importante, el agresor siente remordimiento porque se reconoce a sí mismo como objeto de condena por parte de la víctima, por parte de sí mismo y, en la medida en que la víctima la articula en público, también por parte de todos los otros que son conscientes de su obrar mal y que son afectados por el daño (damage) hecho a miembros de su comunidad y, por consiguiente, a la comunidad como un todo. Los otros podrían responder frente al agresor reconsiderando su confianza en él como una persona que quiere actuar de acuerdo con las normas sociales de la sociedad respectiva. Por último, cuando el agresor ha violado la ley, puede enfrentar la persecución legal y el castigo, y esta perspectiva representa todavía un objeto más de remordimiento.

Finalmente, sin restar su importancia, -y este tercer aspecto de las consecuencias del obrar mal es un recordatorio de lo que dije anteriormente sobre la víctima y el agresor-, un acto de obrar mal daña la relación que había existido entre el agresor y las otras personas, y entre él y su víctima en particular. Es importante recordar que esta relación no tiene que ser personal. Incluso en la ausencia de una relación personal entre el agresor y su víctima como miembros de una misma familia, como amigos, colegas o conocidos, el agresor se relaciona con su víctima como un ciudadano del mismo país que está sujeto a las mismas leyes nacionales, o al menos como un ciudadano del mundo, como un ser humano y miembro de la sociedad mundial, de la sociedad de personas que tienen valor moral intrínseco. Depende de razones contingentes que un acto de obrar mal 
(wrongdoing) cause daño a relaciones personales o a relaciones como las que existen entre los ciudadanos de una nación. Pero, inevitablemente, todo acto de obrar mal representa una violación de las normas morales que todas las personas deben respetar, precisamente, en virtud de su valor moral intrínseco y su correspondiente deber de respetar este valor en cada ser humano.

El perdón pone fin a la culpa (blame) sin, por supuesto, hacer desaparecer el pasado. Pero poner fin a la culpa abre un espacio para redefinir las relaciones sociales entre la víctima y su agresor y los otros miembros de su comunidad. El perdón no depende de la voluntad de la víctima de restaurar la relación que existía anteriormente entre él y su agresor ${ }^{21}$. Volvamos al ejemplo de la infidelidad conyugal: un esposo cuya mujer comete adulterio puede perdonarla, pero hacerlo no depende necesariamente de que el esposo esté dispuesto a continuar con su matrimonio ni de que esté dispuesto a volver a amar a su esposa como lo hacía antes. Él podría sentirse incapaz de permanecer en el matrimonio e insistir en el divorcio. Pero, aun así, puede dejar de culpar a su mujer. Él puede dejar de culparla personalmente y puede dejar de culparla en público -si alguna vez lo hizo-. Según el tipo de relación que tengan después del divorcio - evitándose mutuamente o noeste 'dejar de culparla' se manifestará de diferentes modos. En todo caso, el esposo divorciado no denunciará legalmente a su ex-esposa ni difundirá entre sus conocidos que ella es una mujer adúltera en la que no se puede confiar, intentando advertir a la gente y desanimando a los otros de volver a confiar en ella como compañera en un matrimonio o en cualquier otro sentido. El dejar de culpar permite que la víctima, el agresor y las personas que son parte de su comunidad redefinan sus relaciones sociales. Las personas solo pueden confiar en las otras y esperar correctamente que otros confíen en ellas en una red de relaciones sociales estables.

Cuando una víctima ha dejado de culpar al agresor, cuando ha moderado su resentimiento y ha renunciado a cualquier plan de retaliación o venganza y, por consiguiente, ha animado también al agresor a cesar de culparse a sí mismo; la víctima ha perdonado a su agresor y este puede efectivamente dejar de culparse a sí mismo (self-blame). Entonces, la víctima y su agresor pueden redefinir sus relaciones sociales futuras y las normas sociales que esperan que el otro no viole. El

21 Aquí estoy de acuerdo con Govier, 2002, pp. 42-43. El punto queda explícito en la cita de Berel Lang en Govier, 2002, p. 42. 
perdón da lugar a la redefinición del ser social de ambos y a la reparación del daño que el agresor produjo tanto a la víctima como a sí mismo. Y en la medida en que ambos son parte de una red social más amplia, esto también redefinirá sus respectivos roles en esta red.

Dada esta consideración de lo que significa perdonar y los efectos que tiene el perdón, es evidente que lograr el perdón después de un acto de obrar mal es de interés tanto para el agresor como para la víctima. Pero esto todavía no basta para dar una respuesta a las preguntas surgidas anteriormente con respecto al derecho moral de un agresor a ser perdonado y el correspondiente deber de una víctima de conceder el perdón.

\section{Perdón personal y moral}

GRISWOLD HA PROPORCIONADO UN ANÁLISIS de las diferentes condiciones que, idealmente, tienen que cumplirse en el transcurso del proceso comunicativo del perdón tanto por parte del agresor como de la víctima. Por parte del agresor, estas condiciones incluyen: (a) el reconocimiento de la responsabilidad del mal (wrong) que ha sido cometido (Griswold, 2007, p. 49)22, (b) el rechazo del mal hecho (wrong done), esto es, el reconocimiento explícito de su acción como un mal (wrong) (pp. 49-50), (c) la expresión de arrepentimiento (regret) a la víctima (p. 50), (d) el compromiso de adherirse a los principios que prohíben cualquier clase de lesión (pp. 50-51), (e) la comprensión y el reconocimiento del daño (damage) realizado a la persona lastimada (p. 51) y (f) proporcionar una explicación o narrativa del mal (wrong) cometido. Además, por parte de la víctima, estas condiciones incluyen (a) la "renuncia a la venganza", (b) la "moderación del resentimiento", (c) el "compromiso de dejar por completo el resentimiento", (d) el cambio de la imagen de que "el agresor se reduce al agente que hizo los males (wrongs)" (p. 54), (e) la supresión de "cualquier presunción de una decisiva superioridad moral", incluyendo el reconocimiento de la "humanidad compartida por ambos" y (f) la declaración de que el perdón es concedido (p. 58).

De acuerdo con este análisis, para lograr el perdón, el agresor tiene que culparse por la ofensa cometida y reconocer de modo explícito el respeto debido a

22 Todas las referencias posteriores en este párrafo son a Griswold, 2007. 
la víctima. Con esto hace posible que la víctima recupere la confianza en él, en su disposición para volver a actuar de acuerdo con las normas que violó y en respetar adecuadamente a la víctima. Al entrar en el proceso comunicativo del perdón, el agresor ya muestra su voluntad de respetar a la víctima, de respetar el derecho de la víctima a no ser lastimada (burt) o dañada (harm) de ningún modo ${ }^{23}$. Cuando un agresor rechaza entrar en tal proceso, elige ignorar el mal (wrong) que la víctima ha sufrido o su responsabilidad al respecto; reafirma su falta de respeto por la víctima, haciendo explícito que no le importa la víctima en absoluto, ni su bienestar actual, ni su derecho a ser respetada, ni tampoco aquello por lo que la víctima pueda culparle. Filosóficamente, el aspecto más desafiante del proceso del perdón es proporcionar un análisis coherente de las condiciones que el agresor tiene que cumplir para merecer el perdón: su reconocimiento del daño hecho a la víctima (damage) y su narrativa de lo que ocurrió -asegurándole de una manera convincente a la víctima que no lo hará de nuevo-. Después de todo, el agresor tiene que explicar cómo una misma persona, a saber, él mismo, puede reconocer toda la responsabilidad moral por el mal (wrong) realizado a la víctima, reconocer la maldad (wrongness) de la ofensa y, al mismo tiempo, adherirse a las normas de acuerdo con las cuales lo que hizo estuvo, no obstante, mal ${ }^{24}$. Junto con las condiciones que Griswold señala que el agresor debe cumplir, habría que añadir que el agresor debería estar dispuesto a contribuir adecuadamente a la reparación del daño hecho a la víctima.

El análisis de Griswold hace hincapié en la necesidad de que la víctima modere su resentimiento, deje de culpar al agresor y supere su disposición afectiva a buscar la retaliación y la venganza. La víctima tiene que reconocer al agresor como alguien que, aun cuando haya cometido un mal (wrong), merece todavía ser respetado como un agente responsable, esto es, como un agente en quien se puede confiar que actuará de acuerdo con las normas que prescriben respeto para cada ser humano como intrínsecamente valioso y que prohíben la clase de acción que él cometió.

23 Puede haber casos donde un agresor tiene la voluntad de entrar en un proceso comunicativo de perdón con intenciones ocultas, y no por el interés auténtico de que se le conceda el perdón. La psicología motivacional permite una inmensa variación de motivaciones personales y puede ser imposible formular algún tipo de enunciado general que no admita excepciones.

24 Sobre las paradojas del perdón véase: Kolnai, 1973-1974, p. 95ss.; Atkins, 2002, p. 111; Johansson, 2009, p. 538. 
El perdón se logra cuando ambas partes cesan de hecho de culparse y tienen la voluntad de redefinir los términos de su coexistencia futura o, incluso, su relación futura dentro de su respectiva comunidad. Esta comunidad debe tener espacio para ambos, víctima y agresor, como miembros dispuestos a respetar las normas que le subyacen. Idealmente, todos los miembros de la comunidad confían entre sí y esperan que se confíe en ellos, y esto incluye tanto a la víctima como al agresor como sujetos y objetos de confianza. El ser social de la víctima y del agresor serán reparados acordemente. La víctima no se concebirá más a sí misma como esencialmente una víctima que tiene que culpar a su agresor. Y el agresor no se concebirá más a sí mismo como esencialmente un agresor que merece ser culpado por parte de la víctima, por parte de sí mismo y por parte de todos aquellos miembros de la comunidad que se relacionan entre sí de acuerdo con las normas que el agresor violó.

Por otra parte, si la víctima se niega a perdonar al agresor no cesa de culparlo. La víctima se niega a confiar en el agresor como una persona dispuesta a actuar de acuerdo con las normas sociales y morales. Una de las consecuencias de este rechazo es que las relaciones sociales no pueden reconstruirse dentro de una y la misma comunidad. La víctima y el agresor no pueden volver a relacionarse sobre la base de la confianza mutua -la clase de confianza que, aunque a veces débil, es constitutiva de una relación social. Además, en respuesta al rechazo de la víctima a perdonar, el agresor se sentirá impulsado a continuar culpándose por lo que le hizo, y en la medida en que continúe haciéndolo, tampoco será capaz de reparar el daño (damage) que se hizo a sí mismo por dañar a la víctima (wronging). Sin embargo, como Griswold señala, no todas las condiciones que él enumera para lograr el perdón deben entenderse como realmente necesarias para que algún tipo de perdón tenga lugar ${ }^{25}$. Tampoco el conjunto de estas condiciones debe considerarse suficiente para que se dé el perdón entre la víctima y el agresor ${ }^{26}$. La víctima podría perdonar al agresor y dejar de culparle incluso en casos donde el agresor rechaza contribuir con su parte al proceso de perdón. El agresor podría perdonarse a sí mismo y cesar de culparse incluso si la víctima se niega a perdo-

25 Griswold, 2007, Cap. 3.

26 De acuerdo con Griswold, el perdón (forgiveness) -o, más bien el perdonar (forgivingness)-, es una virtud. Véase: Griswold, 2007, pp. 18-19. 
narlo. Y la víctima puede rechazar perdonar al agresor incluso si todas las condiciones de la lista han sido cumplidas. Una respuesta a la pregunta de si determinadas condiciones permiten moralmente el perdón unilateral o no y, bajo qué condiciones, no puede darse antes de responder las dos interrogantes planteadas más arriba: ¿Tiene el agresor un derecho moral a ser perdonado? ¿Y tiene la víctima un deber moral de conceder el perdón? Si el perdón fuera efectivamente un derecho y un deber moral, estos no podrían depender de la cooperación del otro en el proceso del perdón. Pero ¿existe tal deber y tal derecho?

Para acercarse a una respuesta a estas preguntas, me gustaría introducir una distinción entre dos clases de perdón. Existe, por una parte, el perdón personal, que se obtiene cuando una víctima perdona a su agresor como, por ejemplo, a su cónyuge, a un amigo, a un colega o a un conocido. Naturalmente, la posibilidad de conceder esta clase de perdón depende de que esa relación personal existiera previamente entre la víctima y su agresor. En los casos de perdón personal, cuando la víctima perdona a su agresor confirma su interés en restaurar la relación personal que ambos tenían antes de que el daño (wronging) tuviera lugar. Así, una esposa puede perdonar personalmente a su marido infiel y de este modo continuar amándole y teniéndole como su compañero; un amigo puede perdonar a su amigo por su amistad recíproca; un colega puede perdonar a su colega y asegurar la perspectiva de cooperación futura, y uno puede perdonar a un conocido y continuar con él o ella exactamente en los mismos términos que antes. Por otra parte, existe también el perdón moral. Esta clase de perdón se da cuando la víctima perdona a su agresor solo en la medida en que es un ser humano. Esta es la única clase de perdón que se puede dar en los en casos en que la víctima y su agresor no tenían ningún tipo de relación personal previa al obrar mal. Pero, también puede existir cuando la víctima y el agresor sí tenían una relación personal: una víctima puede negarse a perdonar personalmente a su agresor y, sin embargo, concederle el perdón moral. En este último caso, la víctima no perdona a su agresor como su cónyuge, amigo o colega. Tampoco expresa ningún interés en renovar la relación, pero aun así le concede el perdón como a un ser humano ${ }^{27}$.

27 La distinción terminológica entre perdón personal y moral que estoy introduciendo aquí no implica que cuando se concede el perdón personal no exista un mal moral realizado por un agresor a la víctima. 
O'Shaughnessy proporciona un ejemplo de alguien que rechaza perdonar personalmente a su agresor, pero que sí le perdona moralmente (aunque sin introducir explícitamente la distinción entre perdón moral y personal). El ejemplo se encuentra hacia el final de la obra de Shakespeare, The Tempest. Allí Próspero le dice a Sebastián ${ }^{28}$ :

A ti, mi más malvado señor, a quien llamar hermano

incluso infectaría mi boca, te perdono

tu peor falta ${ }^{29}$.

El perdón personal siempre implica el perdón moral: una víctima no puede perdonar a su agresor en cuanto persona cercana e intentar restablecer la relación que antes tenían, sin perdonarlo también moralmente. Cualquier relación personal cercana incluye el mutuo respeto del valor moral o de la dignidad. Sin embargo, el perdón moral no presupone ni implica el perdón personal.

Dados el estatus normativo a priori de cada ser humano, su valor moral o dignidad y su correspondiente invulnerabilidad moral, cabría preguntarse si es necesario otorgar el perdón moral además del perdón personal. ¿Cuál es la función del perdón moral? El perdón moral restablece el respeto de la víctima por su agresor -no como el compañero de una relación cercana, sino como un ser humano con valor moral intrínseco-. Al perdonar moralmente a su agresor, la víctima reconoce que este, a pesar de haberle dañado, no ha perdido por eso su valor moral y todavía tiene derecho a ser respetado como un ser humano con dignidad.

Pero, ¿este reconocimiento de la dignidad y del valor moral, incluso el del agresor por parte de la víctima, depende de que la víctima efectivamente perdone moralmente al agresor? Para responder a esta pregunta hay que recordar en qué consiste el perdón. Desde el punto de vista de la víctima, conceder el perdón significa dejar de culpar al otro y moderar sus sentimientos de resentimiento u odio de tal modo que no den lugar a ningún tipo de retaliación o venganza. Una

28 Sigo la siguiente traducción del Acto 5 escena 1, del inglés clásico al actual, con algunas modificaciones: "As for you, you evil man that I can't even call brother, I forgive you for even your worst sin, all your sins". Véase: http://nfs.sparknotes.com/tempest/page_182.html. Me apoyo, también, en la traducción de la Biblioteca Shakespeare: "A ti, ser perverso, a quien llamar hermano infectaría mi lengua, te perdono tu peor maldad”. (N. del T.) 
víctima puede responder al daño que se le hace con afectos muy intensos, incluyendo los deseos de venganza tales como lastimar, perjudicar o hasta exterminar al agresor. Pero, si entendemos que la moralidad está fundada sobre el valor moral intrínseco o la dignidad, ni siquiera el peor de los perjuicios da el derecho moral a la víctima de dejarse llevar por la venganza y asesinar al agresor. La institución de la ley prohíbe estos actos de venganza. Muchos de nosotros podemos entender los sentimientos de la madre de una niña que cae presa de un criminal que abusa de ella, la tortura y la mata: sentimientos de odio y de venganza que impulsan a la madre a matar al asesino de su hija. Podríamos incluso simpatizar con ella. Estos sentimientos de simpatía, empero, no nos deberían llevar a pasar por alto el hecho de que la madre no tiene el derecho moral ni legal de matar al asesino de su hija. Ella debe dejar el castigo del asesino a las instituciones legales y moderar sus sentimientos de odio y venganza, al menos hasta el punto en que pueda controlarlos y refrenarse de cualquier acción ilegal. Un asesino puede ser sentenciado a cadena perpetua; pero, incluso tras los muros de la prisión tiene el derecho a ser tratado con respeto moral. Este respeto se le debe en la medida en que es un ser humano ${ }^{30}$. Pero, ¿acaso implica esto que la víctima de un crimen tan horrendo tiene el deber moral de perdonar moralmente al agresor?

\section{Perdón: derechos y deberes morales}

Dudo si CONTESTAR a ESTA PREgunta positivamente o, hablando de un modo más general, si extraer conclusiones de principio a partir de estas consideraciones y del reconocimiento del valor humano intrínseco y la dignidad moral en particular. ¿Puede haber un deber moral de la víctima a conceder el perdón personal, o un derecho moral del agresor a ser perdonado personalmente? ¿Puede haber un deber moral de la víctima a conceder el perdón moral, o un derecho moral del agresor a ser perdonado moralmente? ¿Y puede haber un deber moral

$30 \mathrm{Al}$ respecto, estoy completamente de acuerdo con Hill (2000, pp. 114-118). No debería dejar de mencionarse que Kant mismo evita esta conclusión, que para algunos puede parecer contraintuitiva, y argumenta por la legitimidad de la pena de muerte para algunos criminales. Véase: su Metafísica de las costumbres. La doctrina del derecho. Kant, AA VI, pp. 331-337. Pero su aceptación de la pena de muerte en algunos casos no es compatible con su consideración de la moralidad en términos de una dignidad moral que cada ser humano tiene independientemente de su mérito moral actual. 
de conceder el perdón unilateral o de permitir el perdón de sí mismo? Me parece que ninguna de estas preguntas permite una respuesta exclusivamente positiva o negativa. La moralidad del perdón nos lleva a un ámbito donde las demandas morales se encuentran con la esfera personal e interpersonal de un ser humano individual con todas sus complejidades.

Claramente, no hay un deber moral de establecer algún tipo de relación personal con otra persona. Somos libres de elegir a nuestras parejas, a nuestros amigos, y, al menos en alguna medida, a nuestros colegas y otros conocidos. Pero una vez que ya existen tales relaciones, nuestro vínculo no es solo personal sino también moral. Tenemos obligaciones morales respecto de nuestra pareja que no tenemos respecto de extraños. Y, cuando somos víctimas de un acto de obrar mal por parte de alguien con quien estamos vinculados en una relación cercana, no podemos olvidar estos vínculos al momento de decidir si perdonar al agresor o no. Una ofensa por parte de un compañero en una relación cercana no aniquila sin más estos vínculos, aunque sí les causa daño. Y, si luego el agresor cumple con todas las condiciones anteriormente mencionadas para obtener el perdón, si auténticamente busca el perdón, ¿no nos impone con ello el deber moral de perdonar? Nuevamente, quisiera aludir a en un ejemplo mencionado por O'Shaughnessy (1967, p. 346), esta vez de la obra Middlemarch de George Eliot. Dorotea ha ofendido involuntariamente a su esposo y le ha pedido perdón. Mr. Casaubon no puede tener ninguna clase de duda sobre la sinceridad de su demanda pero, no obstante, rechaza concederle el perdón. Dado que su ofensa fue involuntaria, podríamos preguntarnos si lo que le hizo puede correctamente considerarse un mal en el sentido pleno del término. Pero dejando esto de lado, la pregunta es si Mr. Casaubon puede permitirse a sí mismo estar tan herido que ni siquiera su amor por su esposa pueda ayudarle a moderar sus sentimientos de ofensa y dejar de culparla. ¿ No es su falta de voluntad de perdonar la ofensa -después de todo, una ofensa involuntaria- más bien un signo de carencia de amor auténtico por su esposa? Uno quisiera decir que él tiene un deber moral de perdonarla personalmente; un deber que surge del amor que le debería como esposa. Su rechazo a perdonarla le pone en el camino equivocado (put him in the wrong) y revela, incluso, un mal mayor: la carencia de amor auténtico para con su esposa. En este caso particular, la carencia de amor representa una ofensa moral en sí misma. Ella le ama y él la aceptó como su esposa, pero como él no puede corresponder a su 
amor, no debería haberse casado con ella. Como puede concluirse de este ejemplo, las relaciones personales pueden, en algunos casos, imponer derechos y deberes morales a los compañeros, los cuales en algunas ocasiones, podrían incluir los derechos morales de ser perdonados personalmente y deberes morales de conceder el perdón personal.

Si bien somos, al menos en cierta medida, libres de elegir con quien queremos relacionarnos de un modo cercano, no somos libres de decidir quién puede o no ser considerado como miembro de la humanidad. Quienquiera sea un ser humano tiene, simplemente en virtud de su estatus, derechos y deberes morales con todos los seres humanos incluyendo deberes y derechos morales consigo mismo. Ni siquiera el peor de los crímenes puede eliminar la afiliación del agresor a la sociedad humana. ¿Puede esto, empero, imponer a una víctima una obligación moral de perdonar moralmente a un agresor, incluso si el agresor ha cometido un crimen horrendo, incluso si él no busca auténticamente el perdón? ¿Tiene la madre una obligación moral de perdonar moralmente al asesino de su hija, sea que él busque su perdón o no? ¿Tiene la víctima de la tortura una obligación moral de perdonar a su torturador, sea que él busque su perdón o no?

Pienso que a lo anterior debe responderse negativamente. Una víctima podría sentirse incapaz de ver en el agresor algo distinto al agresor, podría ser incapaz de dejar de culparlo y, por consiguiente, negarse a entrar en un proceso de perdón, negarse a dar al agresor una oportunidad de buscar auténticamente el perdón. Y, la víctima no puede ser moralmente culpada por esta incapacidad emocional.

Pero tal caso no solo debería considerarse desde el punto de vista de la víctima; también debería estimarse desde el punto de vista del agresor. Dejo de lado el caso particularmente desafiante de un criminal que, aun siendo consciente de su acción y sus consecuencias, no siente ningún remordimiento ni ninguna necesidad de buscar de un modo auténtico el perdón de la víctima. Puede que tal persona no sea un agente totalmente responsable, puede ser una persona emocional y motivacionalmente discapacitada. En lugar de este caso, me centraré en el ejemplo de un criminal que se encuentra horrorizado con su propio crimen, que se esfuerza por cumplir con todas las condiciones para obtener el perdón de su víctima, que tiene grandes dificultades para proporcionar una narrativa consistente de cómo él mismo pudo cometer ese crimen, que promete que nunca más volverá a cometer tal crimen y que se culpa severamente a sí mismo y busca el perdón de un 
modo muy auténtico. Podría ir tan lejos como ofrecer a la víctima alguna clase de sacrificio personal para demostrar la sinceridad de su remordimiento y el deseo de ser perdonado. Pienso que en tal caso sería moralmente incorrecto por parte de la víctima aceptar el sacrificio si es que no siente ninguna inclinación a concederle alguna vez el perdón. Pero esto no impone a la víctima ningún deber moral de perdonar. Me parece que ni siquiera un criminal auténticamente arrepentido tiene un derecho moral a ser moralmente perdonado.

El perdón moral de sí mismo puede ser lo moralmente correcto para un agresor auténticamente arrepentido, esto es, como respuesta al perdón moral. Pero ¿puede un criminal que busca auténticamente el perdón pero no lo consigue, perdonarse moralmente a sí mismo? De nuevo, pienso que uno debería inhibirse de dar respuestas de principio a esta pregunta. En muchos casos tal criminal será castigado legalmente y él debería aceptar su castigo como justo. Si alguna vez es liberado de la prisión, esto significará que la sociedad lo readmite como un miembro. Bajo circunstancias muy particulares una sociedad podría readmitir un criminal como un miembro sin siquiera castigarlo. Por ejemplo, podría pensarse en las Comisiones de Verdad y Reconciliación de Sudáfrica que animaron a los criminales a admitir y a asumir las responsabilidades de sus crímenes, pero a los que luego se les concedió la amnistía. Después de todo, en el tiempo posterior al Apartheid lo más importante en términos políticos era evitar una guerra civil y reconstruir una sociedad nueva. Asimismo, en la sociedad anterior muchos habían sido tanto víctimas como criminales. El trabajo de estas comisiones puede verse como inspirado por la idea de la dignidad humana auténtica y la vulnerabilidad humana, incluyendo la vulnerabilidad moral.

La libertad o la amnistía podrían no ser suficientes todavía para que el criminal arrepentido ponga fin a su remordimiento y a su autoinculpación. Pero, si la única posibilidad de alivio para él fuera el perdón moral explícito por parte de su víctima, este sería un asunto personal entre él y su víctima. En cuanto la víctima no tiene el deber moral de perdonarle, él no tiene el derecho moral a ser perdonado y, entonces, tendría que vivir con su remordimiento -así como la víctima tendría que vivir con su resentimiento ${ }^{31}$.

31 Aquí, viene a mi mente el conocido caso de Simon Wiesenthal. Como narra en su libro The Sunflower, un oficial agonizante de la SS le pidió, mientras él era prisionero en un campo de concentración, que 
En cuanto a la víctima de un agresor que no busca auténticamente el perdón o es incapaz de ello, concederle el perdón personal no tiene ningún sentido -después de todo, el agresor no tendrá la voluntad o será incapaz de contribuir a reparar la relación personal que previamente existía entre ambos, y la víctima no puede reparar la relación sin su colaboración-. No hay, entonces, expectativa de reparar efectivamente esa relación. Sin embargo, cuando se trata del perdón moral, la víctima debería sentirse moralmente libre de concederlo o no. Al margen de cualquier interés por el agresor, la víctima podría necesitar perdonar para recobrarse de la ofensa recibida y reconstruir su ser social y respeto de sí misma, de un modo que no incluya su 'ser una víctima' en su propia concepción de sí. Este perdón moral unilateral por parte de la víctima es un asunto muy personal que concierne a la víctima y solo a ella. Cuando una víctima se siente emocionalmente capaz de conceder el perdón moral unilateral y cuando este acto es para su propia conveniencia, ella debería sentirse moralmente libre de hacerlo.

Como conclusión, solo me gustaría decir lo siguiente: la práctica de perdonar y perdonarse a sí mismo debería estar configurada por las restricciones normativas que surgen de nuestro deber moral de respetar la dignidad de todos los seres humanos, así como de los deberes morales que surgen de nuestras relaciones personales. Cuando se trata de analizar casos particulares de obrar mal y de perdón, recíproco o unilateral, deberíamos -en lugar de esperar encontrar principios morales abstractos que podemos aplicar con algún rigor- explorar y observar las circunstancias particulares desde los diferentes puntos de vista de las personas involucradas y, entonces, decidir cómo juzgar y actuar de un modo que

le perdonara por sus crímenes contra los judíos. Wiesenthal no le concedió el perdón, pero afirma que posteriormente le atormentó el recuerdo de su rechazo a perdonar. Me parece que este tipo de casos no puede juzgarse sobre la base de principios morales generales. Tanto la necesidad emocional del oficial de la SS de ser perdonado como la respuesta negativa, muy comprensible además, de Wiesenthal, son casos muy personales. Tenemos que vivir con la idea de que pueden existir muchos conflictos personales muy desafiantes moralmente, conflictos para los que no existe una solución moral clara. Estos desafíos representan una dimensión adicional de nuestra vulnerabilidad moral -y de nuestra dignidad moral intrínseca-. Para la documentación de este caso véase: Wiesenthal, 1998, pp. 42-43, y para su discusión: Golding, 1984-1985, pp. 121-37; Govier, 2002, p. 100ss.; Vetlesen, 2011, pp. 143-165. 
respete tanto la dignidad moral de cada individuo como sus propias heridas y sus necesidades: emocionales y sociales ${ }^{32}$.

Referencias

Atkins, T. (2002). Friendship, Trust, and Forgiveness. Philosophia. Philosophical Quarterly of Israel, 29, pp. 111-132.

Dillon, R. (2001). Self-Forgiveness and Self-Respect. Ethics, 112, pp. 53-83.

Duff, A. (1976). Must a Good Man be Invulnerable? Ethics, 86, pp. 294-311.

Fontane, T. (1979). Unwiederbringlich. Theodor Fontane. Gesammelte Werke 2, München: Nymphenburger.

Gamlund, E. (2011). Forgiveness without Blame. Ch. Fricke. (Ed.), The Ethics of Forgiveness (pp. 107-129). New York/London: Routledge.

Goldding, M.P. (1984-1985). Forgiveness and Regret. Philosophical Forum, XXVI, pp. 121-137.

Govier, T. (2002). Forgiveness and Revenge. London/New York: Routledge.

Griswold, C.L. (2007). Forgiveness: A Philosophical Exploration. Cambridge: Cambridge University Press.

Hampton, J. (2007). The Intrinsic Worth of Persons, Contractarianism in Moral and Political Philosophy. D. Farnham. (Ed.). Cambridge: Cambridge University Press.

Hampton, J. (1988). Forgiveness, Resentment and Hatred. J.G. Murphy \& J. Hampton. (Eds), Forgiveness and Mercy (pp. 35-87). Cambridge: Cambridge University Press.

Harbsmeier, C. (2011). Forgiveness and Forbearance in Ancient China. Ch. Fricke. (Ed.), The Ethics of Forgiveness (pp. 13-29). New York/London: Routledge.

32 Me gustaría agradecer a Charles Griswold, a los miembros del Moral Philosophy Club de la CSMN y, en especial, a Andreas Brekke Carlsson, Kari Refsdal, Nicholas Allot y al lector anónimo por sus comentarios críticos a la versión previa de este ensayo. Mis más especiales agradecimientos para Ursula Baumann, cuyo conocimiento, compasión personal y misericordia la hicieron una excelente académica y consejera moral. En un momento de mi escritura de este capítulo, Maria Alejandra Carrasco me proporcionó un fuerte apoyo y ayuda. Mi gratitud a ella es inmensa. Pero yo quisiera hacer énfasis en que todos los errores que quedan siguen siendo míos. 
Hill, T. (2000). Respect, Pluralism, and Justice. Kantian Perspectives. Oxford: Oxford University Press.

Holmgren, M. (2002). Forgiveness and Self-Forgiveness in Psychotherapy. S. Lamb \& J.G. Murphy. (Eds.), Before Forgiving. Cautionary views of forgivenees in Psycotherapy (pp. 112-135). New York/Oxford: Oxford University Press.

Holmgren, M. (1998). Self-Forgiveness and Responsible Moral Agency. The Journal of Value Enquiry, 32, pp. 75-91.

Holmgren, M. (1993). Forgiveness and the Intrinsic Value of Persons. American Philosophical Quarterly, 30, pp. 341-352.

Johansson, I. (2009). A Little Treatise of Forgiveness and Human Nature. The Monist, 92, pp. 537-555.

Kant, I. (1797). Metafísica de las costumbres. (Trad. A. Cortina \& J. Conill). Barcelona: Altaya.

Kolnai, A. (1973-1974). Forgiveness. Proceedings of the Aristotelian Society, 74, pp. 91-106.

Lamb, S \& Murphy, J.G. (2002). Before Forgiving. Cautionary Views of forgiveness in Psychotherapy. New York/Oxford: Oxford University Press.

Murphy, J.G. (2009). The Case of Dostoevsky's General: Some Ruminations on Forgiving the Unforgivable. The Monist, 92, pp. 556-582.

Norlock, K. (2009). Forgiveness from a Feminist Perspective. Lanham, MD: Lexington Books.

O’ Shaughnessy, R.J. (1967). Forgiveness. Philosophy, XVII, pp. 336-352.

Vetlesen, A.J. (2011). Can Forgiveness Be Morrally Wrong. Ch. Fricke. (Ed.), The Ethics of Forgiveness (pp. 143-165). New York/London: Routledge.

Walker, M.U. (2006). Moral Repair. Reconstructing Moral Relations after Wrongdoing. Cambridge: Cambridge University Press.

Wiesenthal, S. (1969). The Sunflower. New York: Shocken.

Winch, P. (1966). Can a Good Man Be Harmed? Proceedings of Aristotelian Society, 66, pp. 55-70. 